\title{
Power Unit for Power Supply of an Autonomous Facility Having Ability to Connect to General Industrial Power Supply in Recuperative Microgeneration Mode
}

\author{
Alexander Khitrov \\ Pskov State University \\ Electric Power Engineering, Electric \\ Drive and Automation Systems \\ Department \\ the Russian Federation \\ khitrov-pscov@mail.ru \\ Yulia Domracheva \\ Pskov State University \\ Electric Power Engineering, Electric \\ Drive and Automation Systems \\ Department \\ the Russian Federation \\ juli-politeh@yandex.ru
}

\author{
Andrei Khitrov \\ Pskov State University \\ Electric Power Engineering, Electric \\ Drive and Automation Systems \\ Department \\ the Russian Federation \\ khitrov.aa@gmail.com \\ Evgeny Veselkov \\ Pskov State University \\ Electric Power Engineering, Electric \\ Drive and Automation Systems \\ Department \\ the Russian Federation \\ wes_el@bk.ru
}

\author{
Sergei Loginov \\ Pskov State University \\ Electric Power Engineering, Electric \\ Drive and Automation Systems \\ Department \\ the Russian Federation \\ lsy1@mail.ru
}

Abstract - Fundamental and exploratory research in the field of energetics and rational nature management is currently focused on getting results in the field of the effective development and functioning of energy systems. Such systems are based on modern electrical equipment, including electrical machines and controlled power converters (active rectifiers and regenerative units (AC/DC), direct voltage converters (DC/DC), inverters (DC/AC)), conventional and non-traditional electric power based on renewable energy sources (RES).

The Program of basic research in the Russian Federation on a long-term period (2021-2030 years) comprises the actual problems of development of energy supply, energy efficiency, renewable and alternative sources in industry and agriculture, including the issues of production technology, of conversion and storage of electric power.

Electric power from the renewable energy sources requires its continuous correction, equalization and buffering i.e. a control system for the system operating modes.
The paper presents a project of the power unit that provides both autonomous and traditional operation of a power plant having the possibility of recuperating electrical energy into the network. The structure and the composition of such a power unit is proposed, basic control strategies for an autonomous power generating plant having a capacity of up to $15 \mathrm{~kW}$, operating from the variable low speed engine, also having the other sources of alternative energy with the possibility of power accumulation are considered.

Keywords - autonomous power facility, microgeneration, module power systems control, recuperation.

\section{INTRODUCTION}

Federal Law of the Russian Federation of December 27, 2019 No. 471 "On the amendments of the Federal Law "On Electric Power" in part of the microgeneration development" has defined the concept - "microgeneration facility"[1]. It is the facility for the production of electrical energy belonging on the right of ownership or on other legal grounds to a consumer of electrical energy, and its power receivers are technologically connected to power 
supply network facilities with a voltage level of up to 1000 $\mathrm{V}$, as well operating on the basis of using renewable energy sources (including but not limited to). The facility is used by the consumer for the production of electrical energy for both covering his own household or industrial needs and selling it in the manner prescribed by the main provisions of retail markets functioning if the amount of electric power produced by this facility does not exceed the maximum value of the connected power receivers of the consumer and is not more than $15 \mathrm{~kW}$ [1-2].

In other words, it is made possible to sell excess electricity to the network and subsequently to have an income, in agreement with the utilities company, from the autonomous power source on the basis of using renewable energy sources (wind power plant, solar panels, hydrogenerator set on water body, etc.) having a power of up to $15 \mathrm{~kW}$ of the three-phase load (3x400 V, $50 \mathrm{~Hz})$.

Electric power from renewable energy sources requires continuous correction, equalization and buffering of the power values, that is, a control system for operating modes.

The project seems to be relevant, given the New Professions Atlas up to 2030. In the field of energy generation and accumulation new professions include [3]:

- local power supply systems specialist;

- recuperation systems designer;

- microgeneration systems developer;

- power generation systems modernization manager.

Local power systems specialist is engaged in development, implementation and maintenance of low power generation systems (wind, solar, bio, etc.). This type of competence can be used for the owners of country houses as well as in designing vertical farms.

Recuperation system designer is a specialist who develops technological solutions for capturing excess power of moving vehicles, primarily during braking of road transport, subway trains and urban electric transport. There is nothing revolutionary in electric energy recuperation, as it applied now mostly in railway transport, trams and trolleybuses. But recuperation in autonomous power supply systems has just been started practicing.

Microgeneration systems developer is a specialist in developing and designing new technological solutions related to energy microgeneration according to customer requirements. Microgeneration is rapidly growing all over the world including Russia but it is often the case that the standard solutions cannot be used for one reason or another, for example, due to climate, and the development of specialized systems to meet the particular factors is required.

In addition, expenditure on the elements of an autonomous-network electric power plant is getting reduced in the structure of production costs for the reason of expanding production of solar panels, inverters, accumulator storage batteries and supercapacitors. There has been a downward tendency of the cost of the permanent magnet synchronous motors (PMSM) that are increasingly used as starter-generators for autonomous-network electric power plants.

\section{BASIC POWER FACILITY MODULES}

According to forecasts, private alternative energy will be actively being developed in the next 10-20 years. Technologies for production, transferring and storing energy will be automated with the optimization of the operating modes.

The starting data for the power facility design are determined by the desire to create an autonomous power plant for the own needs having the three-phase power of up to $15 \mathrm{~kW}$ and the possibility of accumulating electrical energy and recuperating it to the network.

Let's determine the main modules for the power facility - microgeneration module system.

The algorithm for switching the operating modes of the facility is designed for solid-state relays (SSR) applying. SSR is module semiconductor block made using hybrid technology and consisting of power switches using MOSFETs, IGBTs, thyristors, triacs and the optocoupler control circuit that performs the function of a conventional electromagnetic relay coil (Fig. 1).

Modern SSRs using MOSFETs are capable of withstanding overvoltages of up to $400 \mathrm{~V}$ whereas SSRs using IGBTs - up to $1700 \mathrm{~V}$ at currents of 320-400A, and SSR using thyristors - up to $1600 \mathrm{~V}$ at currents of 320A in single-phase networks and at currents of $120 \mathrm{~A}$ in threephase networks.

Fig 2. shows the network part M1 of the autonomousnetwork electric power plant. The input of the system is global electrical network (3x400V four-wire circuit) with a bidirectional electric energy meter (e.g. A1820RAL-P4GDW-4) [4]) connected to the object by circuit breaker QS.

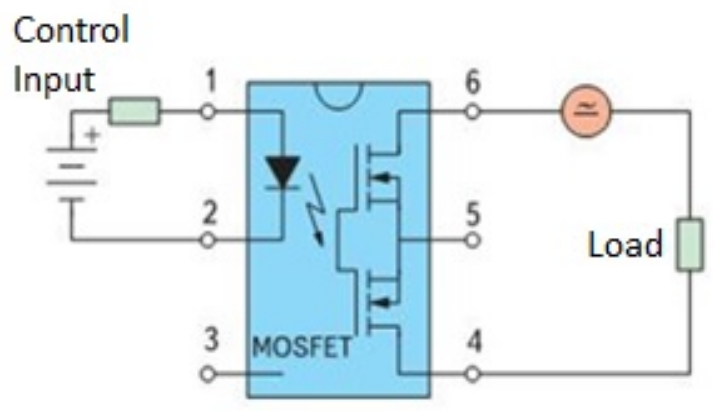

Fig. 1. Solid-state relay. 


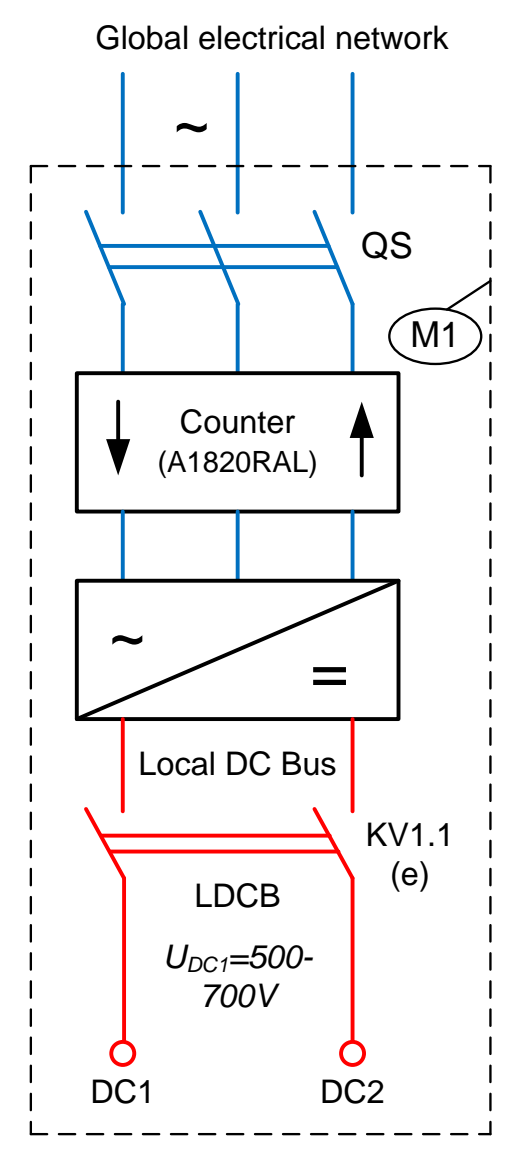

Fig. 2. The network module of the power facility.

Power module of active front end (AFE) rectifier (recuperative converter) (e.g. EPV-R-TPPT-32-380-600, Manufacturer: «CHEAZ-ELPRI», Cheboksary, RF) is designed to interact with network. It provides the creation of the local direct current bus (LDCB) for connection to one or more sources of power generation and storage as well as to local controlled frequency converters with induction motors (pumps, fans, air conditioners, etc.).

Direct current SSR KV1.1 provides the connection of adjustable voltage $U_{\mathrm{DC} 1}(500-700 \mathrm{~V}$, 40A, e.g. 5P20.10G140-6, Manufacturer: CJSC «Proton-Impuls», RF) both when consumers are powered by network and in the mode of transferring (selling) the excess power produced by alternative source (recuperation mode).

Fig. 3 schematically shows the power facility renewable energy sources, at least one three-phase electric generator converting potential or kinetic energy, the solar battery modules conventionally connected, forming a single-phase alternating voltage when SSR KV1.0 is switched on, and providing the battery charger, if necessary, when SSR KV2.0 is switched on (L, N to Fig. 4).

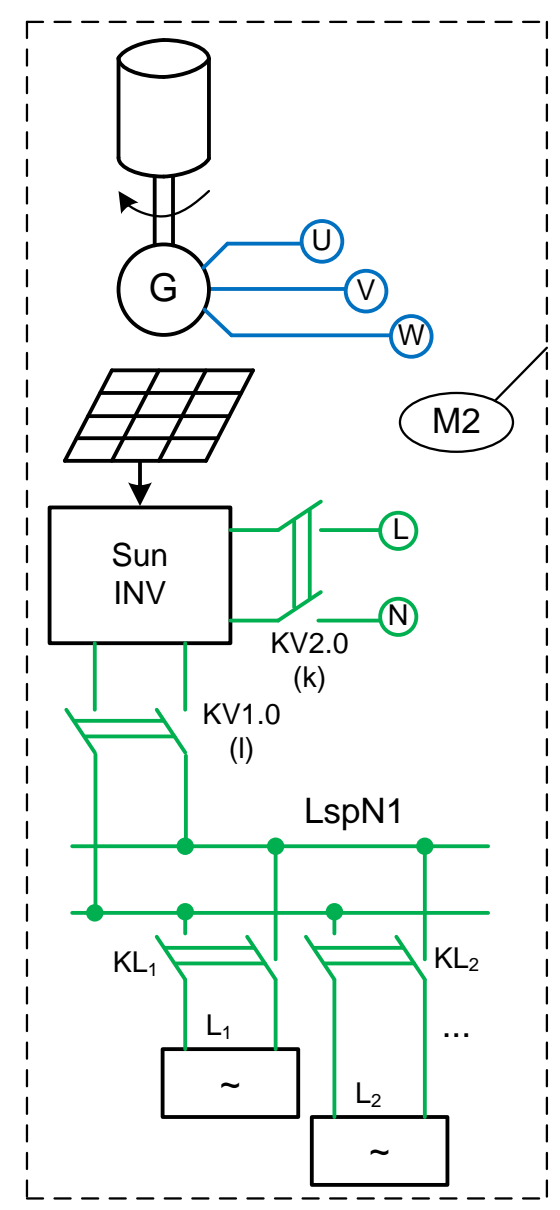

Fig. 3. The renewable energy sources module of the power facility

Renewable energy sources module M2 may include: solar panels (sources of DC voltage of the required level with an inverter (Sun INV in Fig. 3)), wind generator or wind park, some other prime mover using thermal energy (rotary-vane external combustion engine, Stirling engine, gas electric generator using the energy of the natural gas stored in the gasholder) or hydroelectric generator using potential and kinetic energy of water.

The number of these sources is determined by the power requirements of the whole power facility and by technical and economic parameters including the costs of implementation.

Solar panels and an inverter (e.g. solar inverter SOFAR 5KTLM-G2 [5]) create the local single-phase AC network (LspN1 connected with SSR KV1.0, e.g. MD-xx44.ZD3 from KIPPRIBOR, RF) having a power of up to $5 \mathrm{~kW}$. Switching on SSR KV2.0 provides, if necessary, recharging the battery pack (or $48 \mathrm{~V}$ supercapacitor) module M4 (Fig. 4). Fig. 4 shows the basic structure of the power unit forming a three-phase local AC network $(3 \mathrm{x} 400 \mathrm{~V}, 50 \mathrm{~Hz})$ and providing the communication with M1 and M2 modules. The dashed parts M1 and M2 of Fig. 4 are the corresponding parts of the modules presented in Fig. 2 and Fig. 3 (DC1 and DC2 in Fig. 2 and Fig. 4; L, N, U, V, W in Fig. 3 and Fig. 4). 
Energy storage device M4 is connected with direct current SSR KV1.2 which can be switched on to start initially a vertical-shaft-type wind turbine (together with three-phase SSR K3.Start) using an inverter (INV, e.g. Unidrive SP). The second local single-phase AC network (LspN2) can be created, if necessary, using the network single-phase inverter NetINV (48DC/220AC, e.g. TS1500-248B (48-220V), MeanWell (MW)). In the structure designed, there is an option of providing the local singlephase AC network by switching SSR KV1.3 and connecting the inverter to the buck DC/DC converter having an output voltage of $42-60 \mathrm{~V}\left(\mathrm{U}_{\mathrm{DC} 4}\right)$.

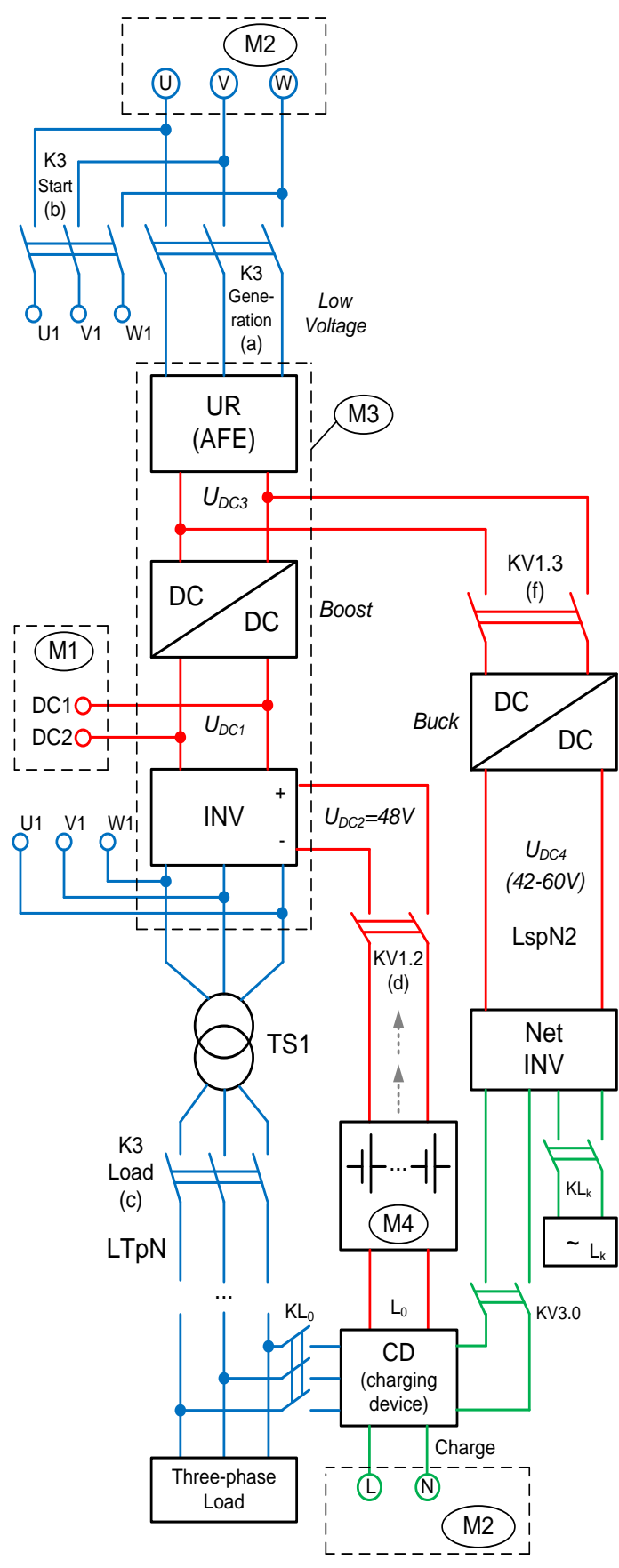

Fig. 4. The power unit of the power facility.
The rectifier-inverter unit $\mathbf{M} 3$ is the core of the whole power unit. It provides the generating local three-phase AC network (LTpN) and connecting sources, power receivers and energy storage via DC bus using is the boost DC/DC converter [6].

Three-phase AC voltage LTpN of the microgeneration module system is formed at the output of M3 inverter INV and the electric load is connected via transformer TS1. The load may include charging device CD for recharging the accumulator batteries of M4.

A large number of types of the autonomous power plants can have a variable speed of the prime mover (e.g. wind turbines having the Savonius rotor system, rotaryvane external combustion engine, hydrogenerator). The variables speed of the system in the range from 300 to 750 rpm does not allow to ensure the normal functioning of the three-phase inverter or requires applying the generators of a special construction with a large number of poles.

One of the tasks of the microgeneration module system is to provide the consumer with the constant frequency of the three-phase supply voltage $(50 \mathrm{~Hz}, 3 x 400 \mathrm{~V})$. For variable shaft speed systems the PMSM having the speed of 1500 or $3000 \mathrm{rpm}$ can be used. (e.g. PMSM of VDM-100 type from JSC “Uralelectro”, RF [7]).

The technical implementation of module M3 is a complex task, such modules are not produced by industry but become a viable proposition. The connection to generation source is made with three-phase SSR K3.Generation.

The module comprises an active front end rectifier (AFE) or uncontrolled rectifier (UR), a DC/DC converter and an inverter having the option of connecting to LDCB via DC1 and DC2 of M1 (DC+ and DC- inputs), for example, frequency converters of the series Unidrive (Control Techniques) or ACS (ABB).

One of the implementation variants is presented in [8]. For transferring electric power from PMSM to LDCB a $\mathrm{DC} / \mathrm{DC}$ converter is provided. The $\mathrm{DC} / \mathrm{DC}$ converter includes the uncontrolled rectifier, H-bridge having 2 or 4 high-speed power IGBTs, high-frequency transformer working at a frequency of $20-100 \mathrm{kHz}$, and the bridge performed with a half-wave rectification and Schottky diodes and connected to the secondary winding of the transformer.

\section{BASIC STRATEGY FOR CONTROLLING POWER FACILITY OPERATING MODES}

Let's consider the main operating modes of the microgeneration module system in accordance with the structure given in Fig. 4from the standpoint of the traditional logic of technological processes control.

Let's introduce the Boolean variables a, b, c, d, e, f (in brackets in Fig.2 and Fig.4).

a-switching on/off the mode of power generation from the prime mover (from PMSM). 
Environment. Technology. Resources. Rezekne, Latvia Proceedings of the $13^{\text {th }}$ International Scientific and Practical Conference. Volume 3, 142-147

b - switching on/off the starting mode from 48V DC source.

c - switching on/off the load for the local three-phase network $(\mathrm{LTpN})$ of the power facility.

$\mathrm{d}$ - connecting/disconnecting the energy storage M4 to the DC bus of M3.

e - connecting the global electrical network to the DC bus of M3.

f - providing the local single-phase network (LspN2) using a buck DC/DC converter.

For control of the power facility operating modes the AC and DC SSR controlled with the direct voltage of up to $24 \mathrm{~V}$ by a programmable logic controller (PLC) may be used.

Following the analysis of the four input variables (a-d), let's introduce new variables:

- $G=a \cdot c \cdot \overline{b+d}$ - establishes the generation mode from the renewable energy source.

This mode should be switched on when the load of the local network is connected ( $c=1$ ), the generation mode from the PMSM has already switched on $(\mathrm{a}=1)$, and start of the PMSM had been completed after the DC source M4 had been disconnected $(b+d=0)$.

- $\quad S=b \cdot d \cdot \overline{a+c}$ - establishes the start mode for PMSM when connecting the DC source $48 \mathrm{~V}$.

Table 1 shows the states of the four variables for determining the basic operating modes of the power facility. The rows with forbidden modes have been excluded from the table.

The basic operating modes of the microgeneration module system are highlighted in bold.

For the basic operating modes 7-9 the Boolean functions Y1, Y2, Y3 has been synthesized.

$Y 1=G \cdot \bar{e} \cdot \bar{f}-$ control function for operation of the local three-phase network (LTpN).

$Y 2=G \cdot \bar{e} \cdot f-$ control function for operation of the local three-phase network (LTpN) and the option of the local single-phase network (LspN2).

$Y 3=a \cdot \bar{b} \cdot \bar{c} \cdot \bar{d} \cdot e-$ control function for providing the recuperation of excess electric power generated to the global electrical network (QS = 1).

Fig. 5 shows the test bench having a power of $1,5 \mathrm{~kW}$ set up at the Electric Power Engineering, Electric Drive and Automation Systems Department of Pskov State University (PskovSU).
TABLE 1 OPERATING MODES

\begin{tabular}{|c|c|c|c|c|c|}
\hline № & G & S & $\mathbf{e}$ & f & Operating Mode \\
\hline 0 & 0 & 0 & 0 & 0 & Switched Off \\
\hline 1 & 0 & 0 & 0 & 1 & $\begin{array}{l}\text { Power supply from the solar panels of } \\
\text { M2 module if available and connected to } \\
\text { SSR KV1. } \\
\text { Providing the local low-power single- } \\
\text { phase AC network for supplying the } \\
\text { single-phase AC load using using the } \\
\text { DC/DC converter and the network } \\
\text { single-phase inverter. }\end{array}$ \\
\hline 2 & 0 & 0 & 1 & 0 & $\begin{array}{l}\text { Operating from the global three-phase } \\
\text { AC network via the recuperative } \\
\text { module M1 providing the local network } \\
3 \times 400 V \text { having a power of up to } 15 \mathrm{~kW} \text {. } \\
\text { Reactive energy accumulation. } \mathrm{QS}=1 \text {. }\end{array}$ \\
\hline 3 & 0 & 0 & 1 & 1 & $\begin{array}{l}\text { DC bus } \mathrm{U}_{\mathrm{DC} 4} \text { is additionally created. A } \\
\text { buck DC/DC converter is used. }\end{array}$ \\
\hline 4 & 0 & 1 & 0 & 0 & $\begin{array}{l}\text { Starting a wind power plant from an } \\
\text { external } 48 \mathrm{~V} \text { DC source. }\end{array}$ \\
\hline 5 & 0 & 1 & 0 & 1 & $\begin{array}{l}\text { DC bus } \mathrm{U}_{\mathrm{DC} 4} \text { is additionally created. A } \\
\text { buck DC/DC converter is not reqired. }\end{array}$ \\
\hline 6 & 0 & 1 & 1 & 0 & $\begin{array}{l}\text { Starting a wind power plant from the global } \\
\text { electrical network while the } 48 \mathrm{~V} \text { DC } \\
\text { source is disconnected from inverter INV. } \\
\text { Carried out briefly by the operator for the } \\
\text { initial start. }\end{array}$ \\
\hline 7 & 1 & 0 & 0 & 0 & $\begin{array}{l}\text { Generation from a wind power plant. } \\
\text { Providing the local autonomous network } \\
3 \times 400 \mathrm{~V} \text { having a power of up to } 15 \mathrm{~kW} \\
\text { (output variable Y1). }\end{array}$ \\
\hline 8 & 1 & 0 & 0 & 1 & $\begin{array}{l}\text { Generation from a wind power plant. } \\
\text { Providing the local autonomous network } \\
3 \times 400 \mathrm{~V} \text { having a power of up to } 15 \mathrm{~kW} \\
\text { and additionally DC bus } \mathrm{U}_{\mathrm{DC} 4} \text {. A buck } \\
\text { DC/DC converter is used (output } \\
\text { variable Y2). }\end{array}$ \\
\hline 9 & 1 & 0 & 1 & 0 & $\begin{array}{l}\text { Energy recuperation to the global } \\
\text { electrical network after switching off the } \\
\text { local } 3 \times 400 \text { network (variable } c \text { changes } \\
\text { from } 1 \text { to } 0 \text {, and variable } e \text { from } 0 \text { to 1) } \\
\text { (output variable Y3). }\end{array}$ \\
\hline
\end{tabular}

The test bench allowed to carry out the studies, that confirmed the efficiency of the innovative microgeneration module system presented in the authors publications $[6,9,10]$.

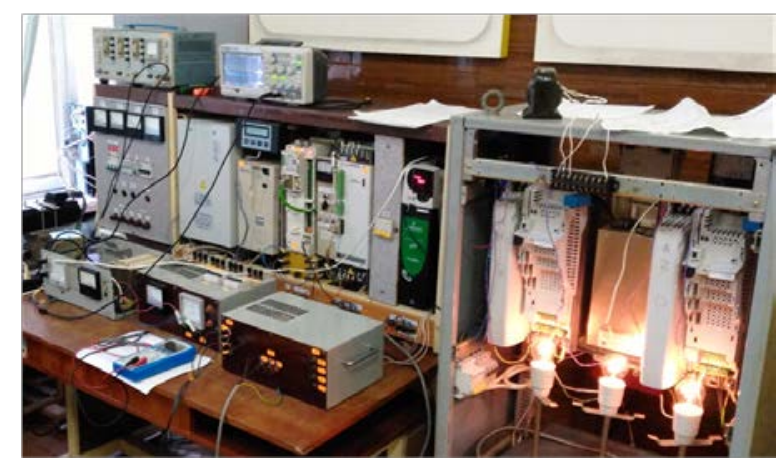

Fig. 5. Test bench.

The studies carried out correlate with the data published in [11], which indicated that "one of the problems of electromechanics, which has not received a high effective 
solution, is the conversion of the mechanical energy of the driving shaft having the variable speed into the electrical energy with the specified quality indicators: stabilized AC voltage and frequency or stabilized DC voltage”.

\section{CONCLUSIONS}

1. The module structure for the microgeneration facility has been developed.

2. It is recommended to apply a permanent magnet synchronous machine (PMSM) as the electric generator for the wind power plant [12].

3. The limited possibilities of output voltage control in the structures with PMSM without applying mechanical or electrical multiplicators require the creation of the special power unit of the module type, consisting of a rectifier module (controlled or uncontrolled), a boost DC/DC converter and a conventional three-phase inverter.

4. The experimental studies have shown the efficiency of the individual modules of the power facility with the admissible values of the indicators of electrical power quality [9, 13].

\section{REFERENCES}

[1] Federal Law of the Russian Federation of December 27, 2019 No. 471 "On the amendments of the Federal Law "On Electric Power" in part of the microgeneration development". (In Russian).

[2] Order of the Government of the Russian Federation No. 3684-r of December 31, 2020 "Program of fundamental scientific research in the Russian Federation for the long-term period 2021-2030. (In Russian).

[3] T.A. Tonunts. Atlas of New Professions. Power generation and energy storage. Professions that will appear before 2030. Izdatel'skie reshenija [Publishing solutions]. 2020, 40 p.(In Russian).
[4] Alpha A1800. Multifunctional microprocessor-based electricity meters of the ALFA series. Moscow: Elster Metronica, 2010. 25 p.

[5] Omega. Solar Inverter for Water Pump. User manual. [Online]. Available: http://www.masterbattery.es/manuales/ Omega_Water_Pump.pdf [Accessed: Mar. 20, 2021].

[6] Khitrov A.A., Khitrov A.I., Ilyin A.V., Domracheva Y.V, Fedorov D.S. Electric energy generation in autonomous energy supply module having rotary expansion engine. Environment. Technology. Resourses. Proceeding of the 12th International Scientific and Practical Conference. June 20, 2019. Volume Ш. p. 109-113.

[7] Electrotechnical plant "Uralelectro" of Mednogorsk. [Online]. Available: http://ural-motor.ru/[Accessed: Mar. 20, 2021].

[8] Wind farm with several wind turbines. Patent RU 2725167 C1. Brombach, Johannes (DE), Penalty, Christian (DE). Application 2019133661,23.03.2018. Published 30.06.2020 Bu1.№19.

[9] Khitrov A.A., Khitrov A.I., Veselkov E.L., Tikhonov V.I. Investigations of Electric Power Quality in Autonomous Low Power Plant. Environment. Technology. Resourses. Proceeding of the 11th International Scientific and Practical Conference. June 1517, 2017. Volume Ш. p.136-139. Rezekne.

[10] Plokhov I.V., Khitrov A.A., Khitrov A.I. Starter-generatornaya ustanovka dlya avtonomnoy sistemy elektrosnabzheniya na baze rotorno-lopastnogo dvigatelya s vneshnim podvodom teploty. [Starter-generator set for autonomous power supply system for external combustion rotary-vane engine]. Patent RF №144521. 27.08.2014. (In Russian).

[11] Mytsyk G.S. About modern solutions of machine-electronic generating systems for small-scale power generation and mobile objects. Elektrichestvo [Electricity]. 2020, №7, pp.22-32. (In Russian).

[12] Permanent magnet synchronous motor 3 to $350 \mathrm{~kW}$ - 1500 to 5500 rpm. [Online]. Available: http://acim.nidec.com/ motors/leroysomer/products/permanent-magnet-synchronous-motors/ lsrpmdyneo [Accessed: Mar. 20, 2021].

[13] State Standard 32144-2013. Electric Energy. Electromagnetic compatibility. Standards of quality of electric energy in generalpurpose power supply systems. (In Russian). 